\title{
Prepubertal height velocity references over a wide
} age range

\author{
B Rikken, J M Wit
}

\begin{abstract}
In order to correct height velocities for the confounders age and sex, SD scores can be calculated using the mean and the SD of the height velocity in the normal population. However, current methods are inappropriate for prepubertal children in the age range in which puberty occurs, because reference groups then consist of a mixed prepubertal/ pubertal population. The mathematical infancy-childhood-puberty (ICP) model opens up the possibility of dissecting the puberty component from the total growth curve. New references for height velocity for prepubertal children calculated over a 12 month interval up to the ages of 15.5 years (boys) and 13.5 years (girls) have been constructed on the basis of adaptations of the ICP model and the Swedish longitudinal growth study.
\end{abstract}

(Arch Dis Child 1992;67:1277-80)

In the evaluation of growth disorders, height velocity is one of the main parameters by which we recognise abnormal growth and judge the impact of therapeutic intervention. When groups of patients are studied, height velocity is usually expressed as SD score to remove the influences of age and sex. However, there is a serious methodological problem in using height velocity SD score for prepubertal children after the age at which children can start puberty. The reference population then consists of a changing mixture of prepubertal and pubertal children so that the mean height velocity of the whole cohort does not represent the mean of the prepubertal children. This also leads to a nonGaussian distribution. Therefore, mean and SD values for prepubertal children have been reported only up to the age of 8.75 years (boys) and 6.75 years (girls). ${ }^{1}$

To extend the age range, the best solution would be to measure height velocities in a large group of prepubertal, healthy, but relatively late maturing adolescents. However, no such data are available. To overcome this problem, in British studies the 50th centile from the whole cohort is used as mean and a hypothetical fixed SD (identical to the SD in late prepubertal years) is taken until the end of growth (CGD Brook and PC Hindmarsh, personal communication). ${ }^{2}$ However, the mixed prepubertal/ pubertal reference population gives an overestimation of the mean height velocity for prepubertal children. Others, including ourselves, have used height velocity SD scores for bone age by substituting bone age for chronological age, assuming that the mean height velocity for bone age in the population equals the height velocity for chronological age. ${ }^{3}$ This assumption is theoretically plausible for healthy children with an average bone maturation, but becomes unlikely for children with an extreme delay or advance of bone age. For example, in children with a delayed bone age the height velocity SD score for bone age is lower than the height velocity SD score for chronological age, due to the downward slope of the mean height velocity curve. Furthermore, no data are available about the SD values for height velocity for bone age.

In this paper we present a new method of obtaining age references for height velocity during the whole period in which healthy children can remain prepubertal.

\section{Methods}

As basis for our model we adapted the infancychildhood-puberty (ICP) model. ${ }^{4}$ The reason for using this model is that it explicitly divides the total growth curve in a prepubertal and pubertal section. However, there are two disadvantages to using the ICP model in its present form as a reference model for height velocity. Firstly, the prepubertal growth curve is composed of two components (the infancy and childhood component), of which the childhood component is supposed to start between 6 and 12 months at a mean age of 9 months. Due to the abrupt introduction of this childhood component there is a sudden increase in mean height velocity at 9 months, which for individual patients with a mean onset of this component may be true but not for the whole reference population. Secondly, from 0-2 years of age the mean and SD of height velocity are presented over intervals of three and six months and thereafter over intervals of 12 months, while it is known that the SD correlates inversely with the length of the interval. ${ }^{5}$

To correct for these problems we adapted this ICP model using the data from the Swedish longitudinal growth study. ${ }^{6}$ The reason for using the Swedish growth study is that it is based on a relatively large sample and that the growth pattern of Swedish children in the 1960s is similar to the present growth of children in many northern European and North American populations. 5 7-10

The first problem of the ICP model was solved by smoothing the transition from the infancy to the childhood component by interpositioning a second degree polynoma between the ages of 0.5 and 3.0 years. This polynoma had to meet the following requirements: 
- At $t=0.50$ it should connect exactly to the infancy component

- At $t=1.75$ it should be identical to the observed height velocity in the Swedish population

- At $t=3.00$ it should connect to the combined infancy + childhood component.

The second problem was approached by recalculating the whole year SDs in the first and second year (J Karlberg, personal communication). With these data and the other Swedish prepubertal SD data (boys $<10$ year, girls $<8$ years), we constructed the best fitting curve, on the basis of the original equation from the ICP model, which is an exponential curve $\left(a+e^{(-b \cdot t+c)}\right)$. Because no data are available of the SD of prepubertal children during the years that some children from the reference population enter puberty, we extrapolated the SD after the ages of 10 (boys) and 8 (girls) years.

The ages of 15.5 years (boys) and 13.5 years (girls) were taken as upper limits because a prepubertal stage beyond these ages is assumed to be non-physiological. The computer program

Table 1 Equations for mean height velocity $(H V)$ on age $t$

\begin{tabular}{|c|c|c|}
\hline \multicolumn{3}{|c|}{$\begin{array}{l}t \geqslant 0.5 \text { and } \leqslant 3 \cdot 0 \text { years: } \\
\mathrm{HV} \cdot \mathrm{r}(t)=\mathrm{a}_{\mathrm{r}}+\mathrm{b}_{\mathrm{r}} \cdot t+\mathrm{c}_{\mathrm{T}} \cdot l^{2}\end{array}$} \\
\hline $\begin{array}{l}a_{\mathrm{r}}: \\
\mathrm{b}_{\mathrm{r}}: \\
\mathrm{c}_{\mathrm{r}}:\end{array}$ & $\begin{array}{r}\text { Boys } \\
27.11 \\
-12.73 \\
2.06\end{array}$ & $\begin{array}{r}\text { Girls } \\
25.28 \\
-11.07 \\
1.73\end{array}$ \\
\hline $\begin{array}{l}t \geqslant 3 \cdot 0 \text { years: } \\
\mathrm{HV}_{\mathrm{c}}(t)=\mathrm{b}_{\mathrm{c}}+2 \cdot \mathrm{c}_{\mathrm{c}} \cdot t\end{array}$ & & \\
\hline $\begin{array}{l}b_{i}: \\
c_{i}:\end{array}$ & $\begin{array}{l}\text { Boys } \\
8 \cdot 54 \\
-0 \cdot 18 \\
\end{array}$ & $\begin{array}{l}\text { Girls } \\
8 \cdot 88 \\
-0 \cdot 21\end{array}$ \\
\hline
\end{tabular}

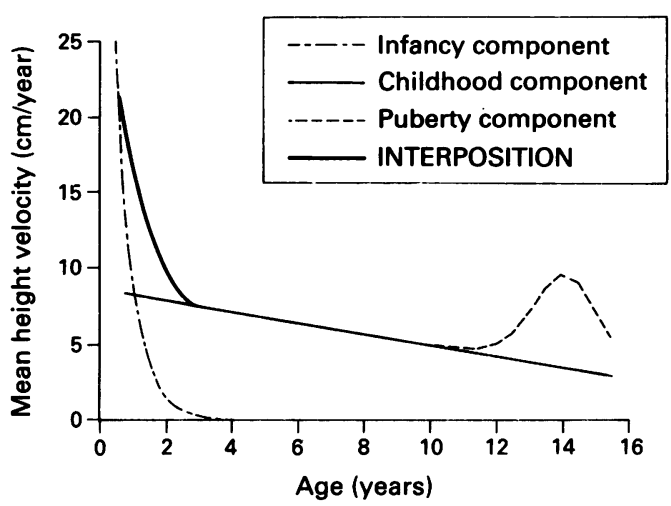

Figure 1 Theoriginal ICP model describing height velocity and ouradaptation. The IPC GrowthStandard:Copyright c 1987. F Karlberg ISBN 91-7900-265-X, and Copyrightc in the US 1989.7 Karlberg TX 2560 182; published with permission.

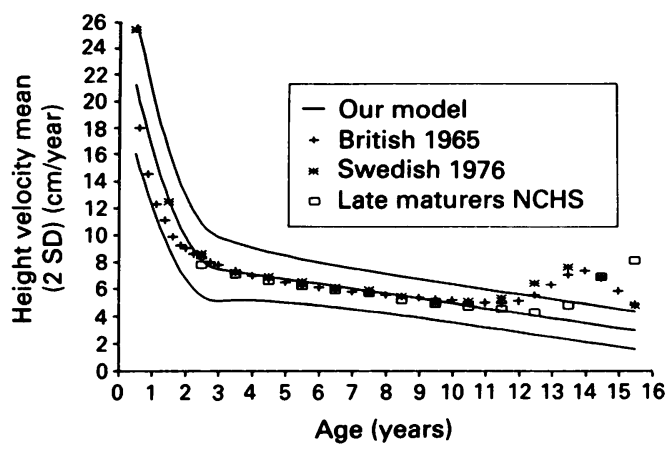

Figure 2 Height velocity ( $\pm 2 S D$ ) according to our model in relation to other references (boys).
EnzFitter version 1.05 (Elsevier Biosoft, Cambridge) was used to calculate the parameters for the curves.

\section{Results}

The equations for the mean height velocity at $0 \cdot 5-3.0$ years (the interposition between the infancy and childhood component), and at ages above 3.0 years (childhood component) are shown in table 1. Figure 1 shows the mean height velocity curves from the original ICP model and the interpositioned polynoma for boys. Figure 2 shows the model for boys in relation to the Swedish ${ }^{6}$ and the British ${ }^{1}$ references and to the American references of late maturers. $^{5}$

The equation for $\mathrm{SD}$ versus age is shown in

Table 2 Equations for $S D$ of height velocity on age $t$

\begin{tabular}{ccc}
\hline HVSD $_{\mathrm{R}}(t)=\mathrm{a}_{\mathrm{R}}+e^{-\mathrm{h}_{\mathrm{R}} \cdot t+\mathrm{c}_{\mathrm{R}}}$ & \\
$\mathrm{a}_{\mathrm{R}}:$ & Boys & Girls \\
$\mathrm{b}_{\mathbf{R}}:$ & 0.691 & 0.820 \\
$\mathrm{c}_{\mathrm{R}}:$ & 0.538 & 0.649 \\
\hline
\end{tabular}

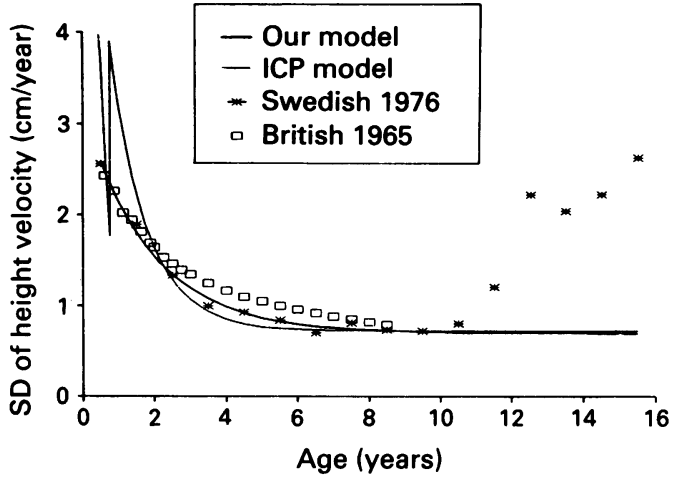

Figure 3 SDofourmodel compared withotherreferences (boys). The IPC GrowthStandard: Copyright c 1987. f KarlbergISBN 91-7900-265-X, and Copyright c in the US 1989. F Karlberg TX 2560 182; published with permission.

Table 3 Reference data for whole year height velocities for prepubertal children using the new equations

\begin{tabular}{|c|c|c|c|c|}
\hline \multirow[b]{2}{*}{ Age } & \multicolumn{2}{|l|}{ Boys } & \multicolumn{2}{|l|}{ Girls } \\
\hline & Mean & $S D$ & Mean & $S D$ \\
\hline 0.5 & $21 \cdot 26$ & $2 \cdot 59$ & $20 \cdot 18$ & $2 \cdot 18$ \\
\hline 1.0 & $16 \cdot 44$ & $2 \cdot 14$ & 15.94 & 1.81 \\
\hline 1.5 & $12 \cdot 65$ & 1.80 & $12 \cdot 57$ & 1.53 \\
\hline $2 \cdot 0$ & $9 \cdot 89$ & 1.54 & 10.06 & $1 \cdot 34$ \\
\hline $2 \cdot 5$ & $8 \cdot 16$ & $1 \cdot 34$ & $8 \cdot 42$ & $1 \cdot 19$ \\
\hline 3.0 & $7 \cdot 46$ & $1 \cdot 19$ & $7 \cdot 64$ & 1.09 \\
\hline 3.5 & $7 \cdot 28$ & 1.07 & $7 \cdot 41$ & 1.01 \\
\hline 4.0 & $7 \cdot 10$ & 0.98 & $7 \cdot 20$ & 0.96 \\
\hline 4.5 & 6.92 & 0.91 & 6.99 & 0.92 \\
\hline $5 \cdot 0$ & $6 \cdot 74$ & 0.86 & 6.78 & 0.89 \\
\hline $5 \cdot 5$ & 6.56 & 0.82 & 6.57 & 0.87 \\
\hline $6 \cdot 0$ & $6 \cdot 38$ & 0.79 & $6 \cdot 36$ & $0 \cdot 86$ \\
\hline 6.5 & $6 \cdot 20$ & 0.77 & $6 \cdot 15$ & $0 \cdot 85$ \\
\hline $7 \cdot 0$ & 6.02 & 0.75 & 5.94 & 0.84 \\
\hline $7 \cdot 5$ & $5 \cdot 84$ & $0 \cdot 74$ & $5 \cdot 73$ & 0.83 \\
\hline $8 \cdot 0$ & 5.66 & 0.72 & 5.52 & 0.83 \\
\hline $8 \cdot 5$ & $5 \cdot 48$ & 0.72 & $5 \cdot 31$ & 0.83 \\
\hline $9 \cdot 0$ & $5 \cdot 30$ & 0.71 & $5 \cdot 10$ & 0.83 \\
\hline 9.5 & $5 \cdot 12$ & 0.71 & $4 \cdot 89$ & 0.82 \\
\hline $10 \cdot 0$ & 4.94 & $0 \cdot 70$ & $4 \cdot 68$ & 0.82 \\
\hline 10.5 & $4 \cdot 76$ & $0 \cdot 70$ & $4 \cdot 47$ & 0.82 \\
\hline $11 \cdot 0$ & $4 \cdot 58$ & $0 \cdot 70$ & $4 \cdot 26$ & 0.82 \\
\hline 11.5 & $4 \cdot 40$ & $0 \cdot 70$ & 4.05 & 0.82 \\
\hline $12 \cdot 0$ & $4 \cdot 22$ & 0.69 & 3.84 & 0.82 \\
\hline $12 \cdot 5$ & $4 \cdot 04$ & 0.69 & 3.63 & 0.82 \\
\hline 13.0 & $3 \cdot 86$ & 0.69 & 3.42 & 0.82 \\
\hline 13.5 & $3 \cdot 68$ & 0.69 & $3 \cdot 21$ & 0.82 \\
\hline $14 \cdot 0$ & $3 \cdot 50$ & 0.69 & & \\
\hline $14 \cdot 5$ & $3 \cdot 32$ & 0.69 & & \\
\hline 15.0 & $3 \cdot 14$ & 0.69 & & \\
\hline $15 \cdot 5$ & $2 \cdot 96$ & 0.69 & & \\
\hline
\end{tabular}


table 2. The SD from our model together with Swedish and British data is illustrated in fig 3. The calculated mean and SD values over the whole prepubertal period are shown in table 3.

\section{Discussion}

Height velocity is commonly used as a sensitive short term parameter for assessing growth and growth intervention. One of the criteria used for the diagnosis of growth hormone deficiency is a height velocity less than the 25 th centile. ${ }^{11}$ Although height velocity is not very stable over time, ${ }^{12}$ a positive change in height velocity is generally considered as a good response to growth promoting treatment. ${ }^{13} 14$

In growth studies in groups of prepubertal children within a wide age range, the use of height velocity expressed in $\mathrm{cm} /$ year is not suitable because of the large confounding effect of age and to a lesser extent, sex. The usual method to overcome this problem, the use of SD scores on the basis of longitudinal growth studies, is only possible for young children. Later on, the pubertal growth spurt, which starts at a variable age, complicates the situation in two ways. First, no reference group consisting of only prepubertal children is available. Second, the variation in the timing of puberty and the great changes in height velocity during puberty destroy the Gaussian distribution. ${ }^{1}$ Because of the drawbacks of the methods currently used to overcome this problem, we searched for a better one.

The ICP model is a mathematical model in which total statural growth is described by a superposition of three equations. ${ }^{15}$ It has been hypothesised that the first and second component would be associated with distinct ways of biological regulation, ${ }^{16}{ }^{17}$ in the sense that the infant component would not be growth hormone dependent. On the basis of our and other observations, this is unlikely. ${ }^{18}$ We therefore felt that there would be no biological reasons to abstain from smoothing the transition between the infancy and childhood components. However, there is little doubt that the pubertal growth spurt is under the influence of other factors, notably sex steroids.

In contrast to the first report on the Swedish longitudinal study ${ }^{6}$ and the description of the data on the basis of the ICP model, ${ }^{4}$ we decided to use only growth velocity data over one year intervals between 1 and 24 months of age, rather than over two, three, and six months. This has no great influence on the mean height velocity, while it reduces the size of the SD, which is much larger over shorter intervals. This implies that our model may only be applied on velocities that are measured over 12 months. It can be argued that during infancy the growth velocity is so high and changes so rapidly, that calculating velocity over a period of a year is too insensitive as a parameter of growth. However, the use of a shorter period in infancy would automatically give rise to the dilemma to choose the age from which the period should be increased to a year, and this woud obviously cause a disruption in the curve of the SD score by age.

Another difference with the original ICP model is that we smoothed the height velocity curve in the second semester by the interposition of a polynoma. This smoothing procedure was necessary for two reasons. First, the use of yearly growth velocities over the whole growth period implied that the sudden acceleration observed by Karlberg ${ }^{4}$ between 6 and 12 months of age would disappear anyhow. Second, the presence of a sharp angle in the curve of the mean growth velocity would lead to methodological artefacts in calculating SD scores.

It is common practice to transform a height velocity always to $\mathrm{cm} /$ year, even when it is measured over a shorter interval than a year. The question is whether such growth velocity could be transformed to SD scores and, if so, which reference data should be used. It should be emphasised that, due to the relatively large measurement error, comparison of velocities measured over unequal intervals is theoretically incorrect. However, if by circumstances no yearly velocities are available, the SD score should be calculated using a higher SD than provided by our model. SD values over two and three month intervals in the first year of life and over six months intervals in the second year have been provided by the Swedish investigators and are indicated in fig $3 .{ }^{4}$ However, exact data on the size of the SD for various intervals at various ages are unavailable, which increases the unreliability of SD scores over short periods.

While our model lacks most of the drawbacks of alternative methods, it should be emphasised that it is based on unproved assumptions with respect to the age references for prepubertal teenagers, as both mean and SD in this age period are obtained by extrapolation. To test the validity of our model, large data sets from late maturing adolescents are needed, which until now are unavailable.

We thank Dr Herman Wijnne for the aid on the mathematical We thank Dr Herman Wijnne for the aid on the mathematical
part of the study and Dr Bart Boersma for critical reviewing the part of the st
manuscript.

1 Tanner JM, Whitehouse RH, Takaishi M. Standards from birth to maturity for height, weight, height velocity and weight velocity: British children, 1965 part II. Arch Dis Child 1966;41:613-35.

2 Hindmarsh P, Smith PJ, Brook CGD, Matthews DR. The relationship between height velocity and growth hormone secretion in short prepubertal children. Clin Endocrino $(O x f)$ 1987;27:581-91.

3 Wit JM, Fokker MH, de Muinck Keizer-Schrama SMPF, $e$ al. (Dutch Growth Hormone Working Group.) Effects of two years of methionyl growth hormone therapy in two dosage regimens in prepubertal children with short stature subnormal response to secretagogues. $\mathcal{f}$ Pediatr 1989;115:720-5.

4 Karlberg J. A biologically-oriented mathematical model (ICP) for human growth. Acta Paediatr Scand Suppl 1989; 350:70-94.

5 Tanner JM, Davies PSW. Clinical longitudinal standards for height and height velocity for North American children. F Pediatr 1985;107:317-29.

6 Karlberg P, Taranger J, Engström I, et al. I. Physical growth from birth to 16 years and longitudinal outcome of the study during the same age period. Acta Paediatr Scand Suppl 1976;258:7-76.

7 Roede MJ, Van Wieringen JC. Growth diagrams 1980 Netherlands third nationwide survey. Tijdschrift voo Sociale Gezondheidszorg 1985;63 (suppl): 1-34.

8 Buckler J. A longitudinal study of adolescent growth. London Springer-Verlag, 1990.

9 Reinken L, Stolley H, Droese W, Oost G. Longitudinale Köperentwicklung gesunder Kinder. II. Größe, Gewicht, Hautfalten von Kindern im alter von 1.5 bis 16 Jahren. Klin Padiatr 1980;192:25-33.

10 Tanner JM, Whitehouse RH. Clinical longitudinal standards for height, weight, height velocity, weight velocity, and stages of puberty. Arch Dis Child 1976;51:170-9.

11 Brook CGD, Hindmarsh PC, Healy MJR. A better way to detect growth failure. BMY 1986;293:1186. 
12 Voss LD, Wilkin TJ, Bailey BJR, Betts PR. The reliability of height and height velocity in the assessment of growth (the Wessex growth study). Arch Dis Child 1991;66:833-7.

13 Tanner JM, Whitehouse RH, Hughes PCR, Vince FP. Effects of human growth hormone treatment for 1 to 7 years on growth hormone deficiency. low birthweight, years on growth hormone deficiency. low birthweight,
inherited smallness. Turner's syndrome and other inherited smallness. Turner's syndrom

14 Brook CGD. Treatment of growth deficiency. Clin Endocrinol $(O x f)$ 1988;30:197-204.

15 Karlberg J. On the modelling of human growth. Stat Med 1987;6:185-92.

16 Karlberg J, Albertsson-Wikland K. Infancy growth pattern related to growth hormone deficiency. Acta Paediatr Scand 1988;77:385-91.

17 Hindmarsh PC, Brook CGD. Normal growth and its endocrine control. In: Brook CGD, ed. Clinical paediatric endocrinology. Oxford: Blackwell Scientific Publications, 1989:57-73.

18 Wit JM, Van Unen H. Growth of infants with neonatal growth hormone deficiency. Arch Dis Child 1992;67:920-5.

\section{Commentary}

Growth and puberty are intimately related and in the adolescent age range it is difficult to dissociate one from the other. There are several variable factors affecting growth at adolescence. Normal children enter puberty at differing ages, from 9.0 to 13.5 years in girls and from 9.5 to 14.0 years in boys. They also progress through puberty at differing rates; the fastest girls pass through puberty in 18 months whereas the slowest boys may take five years. In younger children ( $<8$ years in girls and $<9$ years in boys) it is acceptable practice to use SD scores to compare a child's height with the height of normal children of the same chronological age. Unlike growth in younger children, growth standards for a whole population during the pubertal years have little meaning when applied to an individual; it depends on what stage of puberty an adolescent has attained. Therefore in the adoles- cent years, it is more appropriate to compare rate of growth with children of the same stage of sexual maturation than those of the same chronological age.

Clinicians are often presented with the problem of a child with late puberty and attempt to relate growth rate to chronological age by experience of what is perceived to be normal: is the problem abnormal growth or abnormal puberty? This is an important distinction to make in order to reduce the number of inappropriate endocrine investigations and to limit the use of growth hormone treatment to those who would benefit. This is of particular relevance in this clinical situation as all tests of growth hormone secretion are notoriously difficult to interpret in the phase of growth deceleration of late prepuberty in boys and girls and early puberty in boys. The authors present data that provide a continuum of growth standards throughout prepuberty, so that a meaningful height SD score can be calculated, despite many children being less advanced in sexual maturation than their peer group. Paediatric endocrinologists usually extrapolate normal data for growth velocity in children with absent puberty in a similar fashion to the data in figs 1 and 2 . However Rikken and Wit have been able to quantify this which is a step forward in providing height SD score data with which to determine if growth is abnormal, even in the absence of pubertal development.

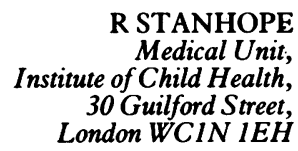

London WCIN IEH

